\title{
Current perspectives and the future of Candida albicans-associated denture stomatitis treatment
}

\section{Stan obecny i perspektywy leczenia stomatopatii protetycznej związanej z zakażeniem Candida albicans}

\author{
Mohammed Moustafa Gad ${ }^{A-D, F}$, Shaimaa Mohamed Fouda ${ }^{B, D, E}$ \\ Department of Substitutive Dental Sciences, College of Dentistry, Imam Abdulrahman Bin Faisal University, Dammam, Saudi Arabia \\ A - research concept and design; $\mathrm{B}$ - collection and/or assembly of data; C - data analysis and interpretation; \\ $D$ - writing the article; $E$ - critical revision of the article; $F$ - final approval of the article
}

\section{Address for correspondence \\ Mohammed Moustafa Gad}

E-mail:mmjad@iau.edu.sa

\section{Funding sources}

None declared

Conflict of interest

None declared

\section{Received on July 16, 2019}

Reviewed on September 8, 2019

Accepted on 0ctober 7, 2019

Published online on March 31, 2020

Cite as

Gad MM, Fouda SM. Current perspectives and the future of Candida albicans-associated denture stomatitis treatment. Dent Med Probl. 2020;57(1):95-102. doi:10.17219/dmp/112861

D0I

$10.17219 / \mathrm{dmp} / 112861$

Copyright

๑ 2020 by Wroclaw Medical University

This is an article distributed under the terms of the

Creative Commons Attribution 3.0 Unported License (CC BY 3.0)

(https://creativecommons.org/licenses/by/3.0/)

\begin{abstract}
Denture stomatitis (DS) is a multifactorial disease, but the proliferation of Candida albicans (C. albicans) is the main causative factor. Different modalities have been suggested for the prevention and treatment of DS. Among the different approaches that have been implemented to inhibit and control DS there are the topical application of antifungal agents, the surface modification of the denture base and the incorporation of antimicrobial agents into the denture base material. Antifungal agents can effectively control DS, but the recurrence of the disease is common. Accordingly, it has been suggested that coating the surface of the acrylic denture base may result in a decreased fungal adhesion. In recent years, nanotechnology has dominated the research, and several nanoparticles have demonstrated antifungal effects.

Therefore, the aim of this article was to review the antifungal effects of the different methods that have been suggested for the prevention and/or control of DS as well as the antimicrobial activity of denture base acrylic resin additives, including nanoparticles. Studies reporting the incorporation of antifungal/antimicrobial agents into the polymethyl methacrylate (PMMA) denture base were included in this review. The PubMed, Web of Science, Google Scholar, and Scopus databases were searched for the articles published between January 2000 and December 2018 using the following key words: dental prosthesis, denture stomatitis, candidiasis, antifungal agents, biofilm formation, polymethyl methacrylate, and PMMA. The antimicrobial material incorporated into the resin may have a superior effect in preventing DS over simply coating the surface of the denture base. However, some antimicrobial fillers can have adverse effects on the physical and mechanical properties of the denture base resin.
\end{abstract}

Key words: polymethyl methacrylate, denture stomatitis, candidiasis, antifungal agents, dental prosthesis Słowa kluczowe: polimetakrylan metylu, stomatopatia protetyczna, kandydoza, czynniki przeciwgrzybicze, proteza dentystyczna 


\section{Introduction}

Denture stomatitis (DS) is an inflammatory reaction that mainly occurs due to a fungal infection by Candida albicans (C. albicans). ${ }^{1}$ According to Newton and Silva Pinto et al., DS is classified into 3 types that appear in the denture-bearing area: dispersed petechiae in the palatal mucosa (type I); diffused erythema (type II); and papillary hyperplasia with diffused erythema (type III)., ${ }^{2,3}$ Many factors contribute to its occurrence, including ill-fitting dentures, continuous wear, poor oral hygiene, and the type of denture base material. ${ }^{1}$ Additionally, any systemic conditions of the patient, such as xerostomia or diabetes, can be predominant factors in the pathology of DS. ${ }^{4}$

The surface properties of the denture base material, such as surface roughness and hardness, can have a significant influence on the incidence of DS. ${ }^{5}$ For example, a denture base material of high hydrophobicity and surface roughness enhances $C$. albicans adhesion and proliferation. ${ }^{1,5}$ In addition, the adequate hardness of the denture base resin is important in order to resist scratches which may occur when using or cleaning the denture. ${ }^{1}$ These properties are adversely affected by denture cleansers, which impacts the long-term success of the prosthesis. ${ }^{5}$ The acrylic denture base is a harbor for microbial colonization; therefore, a denture base material that resists $C$. albicans adhesion and proliferation could reduce the incidence of DS. ${ }^{1,5}$ Different approaches have been implemented to inhibit and control DS, such as topically applying antifungal agents, modifying the denture base surface and incorporating antimicrobial agents into the denture base resin.

\section{Study design}

\section{Search strategy}

This review was designed to address the different methods that have been implemented in the control or prevention of DS, including the latest approaches of incorporating antimicrobial agents and nanofillers into the heat-polymerized polymethyl methacrylate (PMMA). The question posed was as follows: Is coating or incorporating antifungal agents into the PMMA denture base resins more effective than conventional DS treatment? This review was performed according to the PRISMA (Preferred Reporting Items for Systematic Reviews and Meta-Analyses) guidelines (Fig. 1).

The authors performed an extensive bibliographic search using the PubMed, Web of Science (the core collection), Google Scholar, and Scopus databases to identify relevant full-text articles in English which were published between January 2000 and December 2018. The manual search of the reference sections of individual studies did not yield additional articles. The following key words were employed in the search of all the selected databases: dental prosthesis, denture stomatitis, candidiasis, antifungal agents, biofilm formation, polymethyl methacrylate, and PMMA.

\section{Eligibility criteria}

The inclusion criteria comprised in vitro, in vivo and clinical randomized control trials that investigated the different modalities of DS treatment, including the modification of the heat-polymerized PMMA denture base material. Articles which were not related to the field of dentistry were excluded to eliminate any bias in the testing and reporting methods. Review articles and research papers in languages other than English were excluded from the study. Letters to the editor, personal communications, abstracts, and published theses were excluded as well as any unpublished data. Likewise, studies in which antifungal agents were added to tissue conditioners, soft liners and coldcured acrylic denture base materials were excluded as well as studies reporting the effects of these antifungal agents on the surface and mechanical properties of PMMA.

\section{Data management}

The authors (M.M.G. and S.M.F.) independently screened the titles and abstracts only. After duplicates and irrelevant articles were excluded, the full-length articles

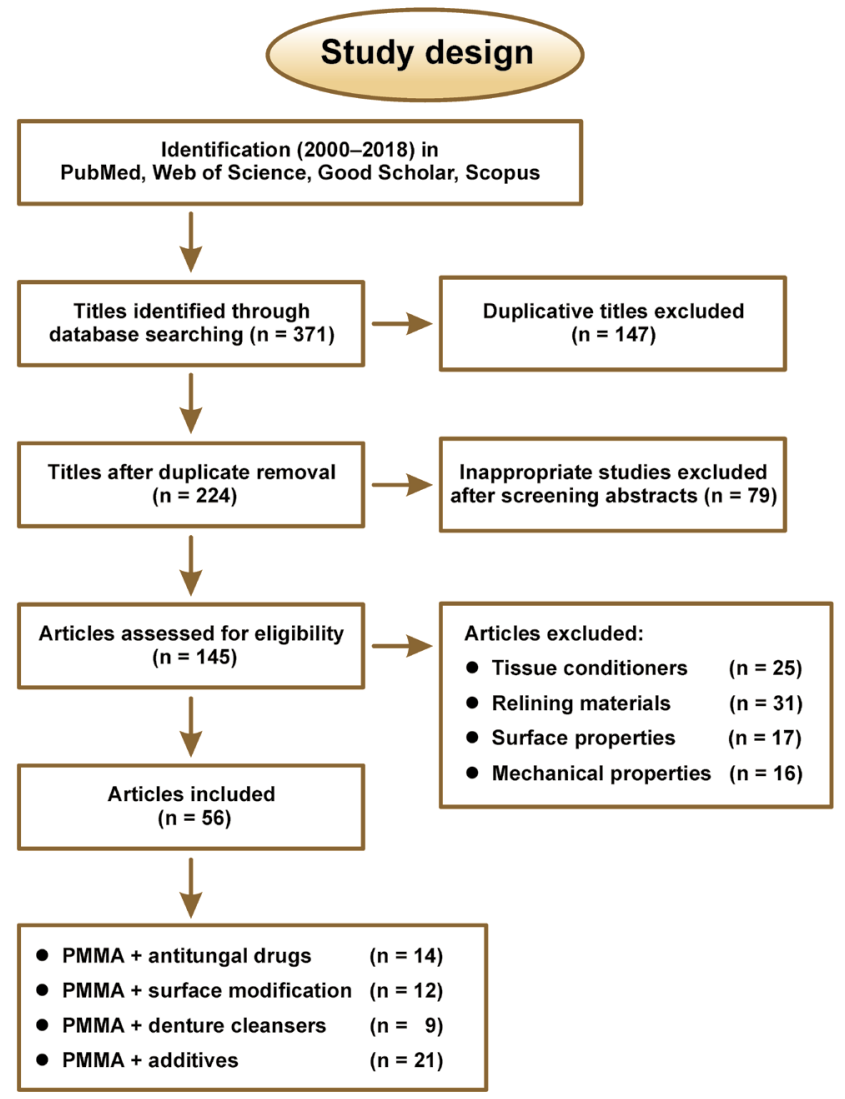

Fig. 1. Study design

PMMA - polymethyl methacrylate. 
were carefully reviewed and the 2 authors decided together which articles to include in the review. The articles were then classified according to the mode of treatment: oral antifungal agents, natural extract-based antifungal agents, cleansing agents, surface modifications of the denture base resin, and antimicrobial resins. The data obtained from the articles categorized under the inclusion criteria were tabulated in the prepared Microsoft ${ }^{\circledR}$ Excel sheet (Microsoft Corporation, Redmond, USA). The authors categorized the information based on author/year, type of study, type of resin, antifungal agents (type, methods of use and applications, type of additive, modifications/ treatment, and mechanism of action), results, and conclusions/outcomes. The effects of different treatment modalities were categorized for a descriptive review. Due to significant variations between the included studies, the data was analyzed descriptively, as the statistical metaanalysis was not applicable.

\section{Results and discussion}

\section{Oral antifungal agents}

Several oral antifungal agents have been suggested for the treatment of DS, such as fluconazole, nystatin, amphotericin B, miconazole, ketoconazole, itraconazole, and clotrimazole (Table 1). ${ }^{6-9}$ They are effective in the treatment of DS, but their drawbacks include toxic side effects and the development of resistant strains. ${ }^{6,9}$ Moreover, DS commonly recurs. Therefore, after the completion of the antifungal therapy, dentures must be disinfected and kept clean in order to avoid the recurrence of DS. ${ }^{10}$ The topical application of antifungal agents is effective only for a short period of time. Besides, these agents are usually negatively affected by the constant flushing of saliva. ${ }^{6,10}$

\section{Natural extract-based antifungal agents}

Several natural products have antifungal and antimicrobial effects, which can be used to combat DS. Natural products are cheaper, less toxic and less likely to induce microbial resistance in comparison with conventional drugs. ${ }^{11}$ However, some of these natural products can show toxicity or cause intolerance; therefore, they must be used cautiously. ${ }^{12}$

It has been found that the Streblus asper leaf ethanolic extract (SAE), when used at a dose of $62.5 \mathrm{mg} / \mathrm{mL}$, reduces the adherence of $C$. albicans. ${ }^{4}$ It has been suggested that SAE affects the cell walls of C. albicans and/or changes the chemical structure of the resin surface. ${ }^{4}$ Pinelli et al. reported that Ricinus communis, when used as a mouthwash 4 times a day, could combat DS by decreasing biofilm formation. ${ }^{13}$ In addition, propolis, when added at $2 \%$ to an oral gel, demonstrated anti-inflammatory effects, curing the lesions caused by $C$. albicans infections. ${ }^{14}$ It has been suggested that propolis may not reduce the quantity of $C$. albicans, but rather it changes the fungus phenotype and acts on the dimorphism of the yeast. ${ }^{14}$ Moreover, the Equisetum giganteum extract contains phenolic compounds and flavonoid heterosides, which have antimicrobial properties. ${ }^{15}$ They showed their antimicrobial effects when brushed on the acrylic resin surface at concentrations of 4 or $8 \mathrm{mg} / \mathrm{mL} .^{11,15}$

Table 1. Antifungal agents used in denture stomatitis (DS) treatment

\begin{tabular}{|c|c|c|c|c|}
\hline Antifungal agent & Formulation & Dose & Effectiveness & Adverse effects \\
\hline Fluconazole & $\begin{array}{c}\text { tablets } \\
\text { suspension }\end{array}$ & $\begin{array}{l}\text { 50-100 mg/day } \\
100 \text { mg/mL per day }\end{array}$ & $\begin{array}{l}\text { effective; } \\
\text { relapse after } 4 \text { weeks }\end{array}$ & nausea, vomiting, diarrhea, abdominal pain \\
\hline Nystatin & $\begin{array}{l}\text { suspension, } 60 \mathrm{~mL} \\
\text { ointment, } 30 \mathrm{~g} \\
\text { tablets }\end{array}$ & $\begin{array}{c}4-6 \mathrm{~mL} / 6 \mathrm{~h} \\
2-4 \text { applications/day } \\
2 / 8 \mathrm{~h}\end{array}$ & $\begin{array}{c}\text { effective; } \\
\text { clinical cure }-87.5 \% \\
\text { mycological cure }-66 \%\end{array}$ & $\begin{array}{c}\text { well-tolerated } \\
\text { uncommon } \\
\text { nausea, vomiting, gastrointestinal effects }\end{array}$ \\
\hline Amphotericin B & $\begin{array}{l}\text { topical } \\
\text { infusion }\end{array}$ & $\begin{array}{c}3 \text { times/day } \\
100-200 \mathrm{mg} / 6 \mathrm{~h}\end{array}$ & $\begin{array}{l}\text { effective; } \\
\text { relapse after } 12 \text { weeks }\end{array}$ & renal, cardiovascular, spinal, and neurological \\
\hline Miconazole & gel, $2 \%$ & $100 \mathrm{mg} / 6 \mathrm{~h}$ & effective & $\begin{array}{l}\text { uncommon; } \\
\text { burning sensation, irritation, nausea, diarrhea }\end{array}$ \\
\hline Ketonazole & $\begin{array}{c}\text { gel, } 2 \% \\
\text { tablets } \\
\text { suspension, } 30 \text { or } 10 \mathrm{cc}\end{array}$ & $\begin{array}{c}3 \text { times/day } \\
200 \text { mg 1-2 times/day } \\
200 \text { mg (20 mL) } 4 \text { times/day }\end{array}$ & effective & nausea, vomiting, abdominal pain \\
\hline Itraconazole & capsules & 100-200 mg/day & $\begin{array}{l}\text { effective; } \\
\text { relapse in patients with } \\
\text { poor oral hygiene }\end{array}$ & nausea, vomiting, diarrhea, abdominal pain \\
\hline Clotrimazole & $\begin{array}{l}\text { gel, } 1 \% \\
\text { tablets, } 10 \mathrm{mg}\end{array}$ & $\begin{array}{l}3 \text { times/day } \\
5 \text { times/day }\end{array}$ & effective & occasional skin irritation, burning sensation \\
\hline
\end{tabular}


The antimicrobial activity of the Equisetum giganteum extract results from inactivating the adhesion proteins and disrupting the microbial cell membrane. ${ }^{11}$ The extract may also increase the hydrophilicity of the acrylic resin surface and reduce its surface energy, thus decreasing fungal adhesion. ${ }^{15}$

The Plantago major extract has shown an antifungal effect against $C$. albicans through the active components aucubin and baicalein. ${ }^{16}$ They strongly inhibit $C$. albicans adhesion and growth by preventing the cell surface hydrophobicity pathway. ${ }^{16}$ Terminalia catappa and the lemon grass extract have been proven to cause a reduction in C. albicans adhesion when used for the immersion of the denture base. ${ }^{17,18}$ Accordingly, they can be used as effective disinfectants against the formation of the $C$. albicans biofilms. ${ }^{18}$ In addition, the immersion of dentures overnight in a $10 \%$ vinegar solution for 45 days has been found to exert a disinfectant effect against C. albicans. ${ }^{3,19}$

\section{Cleansing agents}

Oral mouth rinses are more conservative in the management of DS as compared to systemic drugs..$^{20}$ Several cleansing agents are available for denture immersion, such as sodium perborate, sodium hypochlorite, coconut soap, phosphoric and benzoic acids, chlorhexidine digluconate, and glutaraldehyde. ${ }^{20-23}$ Gornitsky et al. confirmed the antimicrobial effects of sodium perborate-based tablets and suggested the controlled use of these cleansers. ${ }^{20}$ Sodium perborate is an effective denture cleanser when used at a concentration of $3.8 \%$ for 10 min daily. ${ }^{20}$ In addition, sodium hypochlorite $(0.5 \%$ concentration for $10 \mathrm{~min} /$ day) eliminates denture plaque, but it also causes metal corrosion and skin irritation. ${ }^{21}$ The antifungal effects of sodium bicarbonate have been reported at a concentration of $5 \%$; therefore, it can be used for the disinfection of removable prostheses..$^{22}$ Chlorhexidine has excellent antimicrobial effects at a low concentration $(0.12 \%)$ and it is practical for everyday use. ${ }^{23}$

Denture cleansers are effective antimicrobial agents; however, their effects depend mainly on their continuous and proper use, according to the guidelines on preparation and immersion time. ${ }^{24}$ Unfortunately, denture cleansers adversely affect the physical properties of the denture base resin. ${ }^{24,25}$ Several studies have reported an increase in the surface roughness of the denture base resin following the use of denture cleansers, which consequently increased the accumulation of plaque. ${ }^{25}$ Denture cleansers may also cause color changes to the denture base resin and a reduction in the flexural strength. ${ }^{24,25}$ Soft tissue irritation and mild cytotoxic effects have been reported when using glutaraldehyde and sodium hypochlorite, respectively. Additionally, sodium hypochlorite causes the bleaching of the denture base resin. ${ }^{25}$ Furthermore, chlorhexidine causes a burning sensation to the oral mucosa, tooth staining and denture discoloration..$^{23}$

\section{Surface modifications (resin coating)}

The surface roughness of the inner surface of a dental prosthesis is one of the factors that affect the adhesion of C. albicans and biofilm formation. ${ }^{26}$ The adherence of $C$. albicans to the denture base resin followed by the colonization of microorganisms occurs mainly due to hydrophobic interactions and electrostatic forces. ${ }^{27}$ In addition, an increased surface roughness of the denture base resin enhances microbial adhesion ${ }^{28}$ and makes it difficult to detach microorganisms, even with the use of antimicrobial agents. ${ }^{27}$ Therefore, it has been suggested that coating the surface of the denture base resin may decrease microbial adhesion. ${ }^{1}$ Several materials have been used for coating the surface of the denture base resin and reducing $C$. albicans adhesion, such as 2-octyl cyanoacrylate, silane-silicon dioxide $\left(\mathrm{SiO}_{2}\right)$ nanocomposite films, and coatings containing zwitterion or hydrophilic monomers. ${ }^{29-31}$ Ali et al. suggested that coating the denture base resin with 2-octyl cyanoacrylate could reduce C. albicans adhesion by increasing surface hydrophilicity and providing a smoother surface. ${ }^{29}$ Similarly, silane- $\mathrm{SiO}_{2}$ nanocomposite films reduced the surface energy of the coated acrylic resin and increased its hydrophilicity, thus decreasing C. albicans adhesion. ${ }^{30}$

Lazarin et al. found that photo-polymerized coatings containing zwitterion or hydrophilic monomers could reduce the adhesion of $C$. albicans to the acrylic resin, particularly at a high concentration (35\%). ${ }^{31,32}$ They concluded that these coatings changed the chemical composition, but did not alter the hydrophobicity of the surface. A significant decrease in C. albicans adhesion was reported when the surface was coated with sulfobetaine or hydrophilic monomers. ${ }^{31-33}$ They caused changes to the carbon and oxygen content of the acrylic surface, and so did the presence of sulfur. ${ }^{34}$ Applying a zwitterionic coating to the surface of the substrate reduced microbial adhesion, including that of $C$. albicans, and this antibioadherent property was associated with the sulfobetaine component. ${ }^{34}$

A reduction in C. albicans adhesion was detected in the case of certain polymer coatings, such as parylene, which also improved surface wettability. ${ }^{35}$ Accordingly, increasing the hydrophilicity of the denture surface could reduce C. albicans adhesion and microbial colonization. ${ }^{32}$ Park et al. found a significant reduction in the amount of $C$. albicans adhering to the resin surface modified with surface charges and self-bonding polymers. ${ }^{36}$ They suggested that these surface modifications created an electrostatic repulsion between $C$. albicans and the acrylic resin, which prevented the initial attachment caused by hydrophobic interactions and electrostatic forces. ${ }^{36}$ Similarly, Hirasawa et al. reported a significant decrease in the initial adhesion of $C$. albicans to the denture base coated with a crosslinkable copolymer containing sulfobetaine methacrylamide (SBMAm) ${ }^{34}$ Sulfobetaine methacrylamide increases the hydrophilicity of the surface it coats, thus decreasing 
C. albicans adhesion by reducing the hydrophobic interactions between $C$. albicans and the denture base resin. ${ }^{37,38}$

Titanium dioxide $\left(\mathrm{TiO}_{2}\right)$ has been used to coat a number of medical products. It is biocompatible, and it has photocatalytic effects, which allows it to be used to coat the denture base resin. ${ }^{39}$ The $\mathrm{TiO}_{2}$ coating of the denture base resin has shown an inhibitory effect against the adhesion of Streptococcus sanguinis and C. albicans. ${ }^{31,39,40}$

Based on the review of coatings, it can be stated that coating the denture base modifies the surface, changing surface characteristics from rough hydrophobic to smooth hydrophilic, thus decreasing biofilm formation and $C$. albicans adhesion. However, further studies are required to test the biocompatibility of these coatings as well as their durability and resistance to the chemical and mechanical procedures of denture cleaning.

\section{Antimicrobial resin}

\section{(resin with incorporated filler and nanofiller antimicrobial agents)}

The conventional chemical and mechanical methods used to clean dentures are satisfactory in many cases. However, these methods present challenges for some geriatric patients and patients with physical disabilities. ${ }^{19}$ Incorporating antimicrobial and antifungal agents into the denture base resin could be an effective way to eliminate biofilm formation and microbial adhesion. These effects have been investigated in many studies, but biofilms are difficult to eliminate because of their inherent resistance to the incorporated antimicrobial and antifungal agents, in addition to altering the physical and mechanical properties of the resin. ${ }^{41}$

The addition of a fluoridated glass filler or surface pre-reacted glass-ionomer (S-PRG) filler to the acrylic denture base significantly reduces $C$. albicans adhesion without negatively altering the physical properties of the resin. The modified resin releases fluoride ions and acts as a fluoride reservoir (Table 2). ${ }^{9,42,43}$

Microorganisms tend to adhere more to hydrophobic surfaces than to hydrophilic ones through the formation of strong hydrophobic bonds. ${ }^{3}$ Therefore, microbial adhesion is enhanced by the hydrophobic nature of the denture base resin and electrostatic interactions. ${ }^{2,44}$ The addition of methacrylic acid to PMMA creates a negative charge, which produces a repulsive force toward the negatively charged surfaces of most bacteria, thus reducing adherence. ${ }^{45}$ There have been reports on the significant antimicrobial activity of the denture base acrylic resin containing antimicrobial polymers (2-tertbutylaminoethyl methacrylate). While its antimicrobial activity was significant against the Staphylococcus aureus and

Table 2. Types and mechanisms of action of the fillers and nanofillers incorporated into PMMA

\begin{tabular}{|c|c|c|}
\hline Additive & Type & Mechanism of action \\
\hline \multirow[t]{2}{*}{ Glass filler } & S-PRG filler ${ }^{9}$ & $\begin{array}{l}\text { A S-PRG filler is capable of releasing } 6 \text { types of ions }\left(\mathrm{Na}^{+}, \mathrm{Sr}^{2+}, \mathrm{SiO}_{3}{ }^{2-}, \mathrm{Al}^{3+}, \mathrm{BO}_{3}{ }^{3-} \text {, and } \mathrm{F}^{-}\right) \text {and exhibits fungistatic effects against } \\
\text { C. albicans. } \\
\text { Boric acid can destabilize the membranes of C. albicans by decreasing the relative ergosterol content and it causes the } \\
\text { disintegration of the cytoskeletal elements of C. albicans at the hyphal tip, thus inhibiting the growth of this fungus. } \\
\text { Sodium fluoride (NaF) exhibits fungicidal activity; its antifungal effects are ascribed to the interaction of the stannous fluoride } \\
\text { component with the plasma membrane of the yeast cells. } \\
\text { Sodium (N) can create high osmotic stress and kill C. albicans cells, while increasing the doubling time for C. albicans. }\end{array}$ \\
\hline & $\begin{array}{l}\text { fluoridated } \\
\text { glass filler }{ }^{42}\end{array}$ & An acrylic resin modified with fluoridated glass fillers acts as a fluoride-releasing device. \\
\hline \multirow{3}{*}{ Nanofiller } & $\mathrm{AgNPs}^{52-54}$ & $\begin{array}{l}\text { AgNPs wrap around C. albicans cells and cause the disruption of the fungal membrane and the inhibition of the normal budding } \\
\text { process. Silver (Ag) ions or AgNPs are released into the aqueous medium from the acrylic resin to exert their antifungal influence. } \\
\text { AgNPs, with their rapid and broad-spectrum efficacy and the sustained silver cation }\left(\mathrm{Ag}^{+}\right) \text {release, appear to be more effective } \\
\text { antimicrobial agents than micro-sized silver powder [ } \mu \mathrm{m}] \text {, which shows lower antimicrobial activity owing to its limited surface } \\
\text { area. The cation } \mathrm{Ag}^{+} \text {interacts with cytoplasmic components and nucleic acids to inhibit the respiratory chain enzymes and to } \\
\text { interfere with membrane permeability. AgNPs are sensitive to oxygen and convert oxygen into active oxygen through catalytic } \\
\text { action. This active oxygen causes structural damage to microorganisms, which is called the oligodynamic action of Ag. Silver } \\
\text { ions are positively charged, so they interact with the negatively charged cell membranes of bacteria, causing their death due } \\
\text { to an increased cell wall permeability. In addition, Ag adheres to bacterial DNA, RNA, proteins, and enzymes, preventing cell } \\
\text { division and damaging the cellular content of bacteria. }\end{array}$ \\
\hline & $\mathrm{TiO}_{2} \mathrm{NPS}^{41,44}$ & $\begin{array}{l}\text { The antibacterial effect of titanium dioxide }\left(\mathrm{TiO}_{2}\right) \text { occurs due to the deactivation of the cellular enzymes by coordinating the } \\
\text { electron-donating groups, which results in gaps arising in the bacterial cell walls, leading to their higher permeability, and } \\
\text { finally to cell death. The cell components of microorganisms degrade with no release of potentially toxic compounds. } \mathrm{TiO}_{2} \\
\text { demonstrates photocatalytic properties in the presence of photons with wavelengths lower than } 388 \mathrm{~nm} \text {, by which electrons } \\
\text { get excited (the prominent catalytic effect). Free radicals are subsequently formed with such a high level of energy that they can } \\
\text { react with various organic materials and enable their degradation. }\end{array}$ \\
\hline & $\mathrm{ZnO}_{2} \mathrm{NPs}^{60}$ & $\begin{array}{l}\mathrm{ZnO}_{2} \mathrm{NPs} \text { are responsible for the production of reactive oxygen species as well as for the accumulation of the nanoparticles in } \\
\text { the cytoplasm or on the outer cell membranes of bacteria. The antifungal effect might also be attributed to the dissociation } \\
\text { of zinc }(\mathrm{Zn}) \text { ions from } \mathrm{ZnO}_{2} \mathrm{NPS} \text {. }\end{array}$ \\
\hline
\end{tabular}

S-PRG - surface reaction-type pre-reacted glass-ionomer; AgNPs - silver nanoparticles; $\mathrm{TiO}_{2} \mathrm{NPs}$ - titanium dioxide nanoparticles;

$\mathrm{ZnO}_{2} \mathrm{NPs}$ - zinc peroxide nanoparticles; C. albicans - Candida albicans. 
Streptococcus mutans biofilms, it was not significantly effective against $C$. albicans. ${ }^{46}$ Moreover, the surface roughness and wettability of the acrylic resin surface increased, and color changes have also been observed. ${ }^{46,47}$

Adding natural extracts such as henna (Lawsonia inermis) and the seeds of Nigella sativa as fillers in the PMMA denture bases can play a significant role in the prevention of microbial or fungal adhesion and proliferation. ${ }^{48,49}$ Nawasrah et al. found that a natural antimicrobial agent (henna) may control C. albicans proliferation on the denture surface, and that it might serve as a possible method of prevention and treatment of DS. ${ }^{48}$ Thymoquinone (TQ) is the major ingredient of the essential oil obtained from the Nigella sativa seeds, and it has promising therapeutic potential in medicine and dentistry. Al-Thobity et al. reported that adding TQ to the denture base resin could effectively prevent $C$. albicans adhesion and proliferation. ${ }^{49}$ However, even with the significant antifungal properties of natural extracts, their adverse effects on the physical and mechanical properties of the denture base resin may restrict their usefulness. ${ }^{50}$

Antimicrobial and antifungal effects have been reported for nanofillers when they are added to the PMMA denture base materials, forming nanocomposites with superior properties. ${ }^{51}$ Nanocomposites have been investigated in many studies in an attempt to produce a denture base material that is resistant to fungal and microbial adhesion, and subsequently to DS. ${ }^{51,52}$ Several studies have reported the antimicrobial effects of nano-sized particles, such as silver nanoparticles (AgNPs), titanium dioxide nanoparticles $\left(\mathrm{TiO}_{2} \mathrm{NPs}\right)$, zinc oxide nanoparticles ( $\left.\mathrm{ZnONPs}\right)$, and zirconium dioxide nanoparticles $\left(\mathrm{ZrO}_{2} \mathrm{NPs}\right)$ (Table 2).

Silver nanoparticles are biocompatible and have shown strong antimicrobial effects against a wide range of bacteria, viruses and fungi. ${ }^{53,54}$ Consequently, their incorporation into the denture acrylic resin may prevent DS. ${ }^{54}$ They have a smaller tendency to induce microbial resistance as compared to conventional antibiotics..$^{55}$ Although several studies have reported the antifungal properties of the denture base resin containing AgNPs - especially at high concentrations - the nanoparticles caused resin discoloration and did not improve their mechanical properties. ${ }^{54,56}$ The recent studies using silver-containing nanomaterials have suggested that the bacterial toxicity of these materials originates partially from membrane damage and the disruption of ion homeostasis, with unpredictable effects on human health. ${ }^{53,54,57-59}$

The incorporation of ZnONPs into the acrylic denture resin has also been tested and it has been found that they might prevent fungal infections. ${ }^{57,60}$ The results indicate that filling denture base resin materials with commercially available $\mathrm{ZnO}$, calcium oxide $(\mathrm{CaO})$ or $\mathrm{TiO}_{2}$ nanopowders inhibits biofilm formation on their surfaces. ${ }^{51}$

Titanium dioxide nanoparticles are considered to be an excellent filler for several reasons. ${ }^{61}$ Most importantly, titanium-polymer nanocomposites are biocompatible and they exert a non-contact biocidal impact. ${ }^{44}$ In addition to their antibacterial and antifungal properties, $\mathrm{TiO}_{2} \mathrm{NPs}$ are inexpensive and they enhance the mechanical properties of the denture base resin ${ }^{61}$; they also provide the resin with photocatalytic effects. However, their antimicrobial and photocatalytic properties are significant only at a relatively high concentration of $\mathrm{TiO}_{2} \mathrm{NPs}(5 \mathrm{wt} \%)$, which may weaken the resin. ${ }^{39}$ When the $\mathrm{TiO}_{2}$ photocatalyst is exposed to ultraviolet light, it generates oxidative species, which kill microorganisms by damaging their cell walls. Additionally, it has excellent hydrophilicity. ${ }^{39,61}$

Oral hygiene and denture care are important factors in the prevention and treatment of DS. Based on the aforementioned factors, the question raised now is: Which is better - coating or incorporating the antimicrobial agent into the denture base resin? Coatings provide smooth surfaces, which prevents C. albicans adhesion, but they may affect denture retention by obliterating surface details as well as tissue adaptability. Moreover, the mechanical and chemical cleaning of dentures may disturb the coating, leaving a rougher surface with an increased tendency toward microbial adhesion, staining and poor esthetics. Incorporating antimicrobial agents into the PMMA denture base may eliminate the drawbacks of coating by imbedding the agents within the resin matrix.

Good esthetics is highly desirable in the case of removable dental prostheses; therefore, the use of antimicrobial agents, whether they are coated or incorporated, should not compromise the esthetics of the final composites. It has been found that coating does not alter the optical properties of the acrylic resin. ${ }^{37}$ However, over time, the optical properties are affected by the scratches resulting from mechanical cleaning, which makes the surface rougher and increases the susceptibility of the denture to microbial adhesion and staining. Antimicrobial monomers and glass fillers result in minimal color changes to the denture base resin, followed by the $\mathrm{TiO}_{2}$ nanofiller, which causes white discoloration, whereas AgNPs displayed the worst effects on the esthetics, with a greycolored acrylic resin. Silver nanoparticles have been reported to have antifungal properties, but their adverse effects on the esthetics of the acrylic base may limit their clinical use. Therefore, it has been recommended to add them to less visible areas. The same method may be applied to natural extracts, such as henna and TQ, in order to avoid their deteriorating effects on the mechanical and physical properties of PMMA.

In the future, nanoparticle antimicrobial agents may become more common due to their potential antimicrobial activities. The use of nanomaterials with larger active surfaces provides antimicrobial effects at much lower doses, without affecting the PMMA structure. Moreover, some antimicrobial fillers are promising in terms of having the required physical and mechanical properties for denture fabrication. Therefore, further investigations are required to evaluate the correlations between the effects 
of antimicrobial agents and the surface roughness of the denture base resin. Are the resultant antimicrobial effects due to their antimicrobial activity or their action on the surface properties of the acrylic resin? The answer is very important in order to develop an antimicrobial resin that is satisfactory for dental prosthesis fabrication, with longevity and reasonable clinical applications. It is also important to test the resistance of denture coatings to cleaning methods, including brushing and immersion in denture cleansers, before they are used clinically. ${ }^{13}$

The addition of an antimicrobial material to PMMA has been suggested in order to obtain an antimicrobial denture base resin. However, the percentage of the additive which would be effective without altering the physical properties and biocompatibility of the acrylic resin must be considered. Overall, preventing DS is better than managing it after it occurs. In addition, an antimicrobial material incorporated into the resin may be superior to a coating on the surface of the denture base in the prevention of DS. Further studies are required to test the correlations between the antimicrobial effects of nanoparticles and the surface roughness of the acrylic resin, in addition to its durability and aging effects, under simulated oral conditions.

\section{Conclusions}

The present review included studies on the treatment of DS using different approaches. Based on the literature review, it can be concluded that the incorporation of different antifungal agents into the PMMA denture base material can control DS. In addition, coating the denture base resin with antifungal agents and topically applying cleaning agents are both effective in the treatment of DS in vitro. However, most of the published articles were based on in vitro studies, with or without simulating the clinical situations. There is also a lack of studies investigating the long-term effects of these treatment methods, and the relationship between surface properties and nanofiller additives. Therefore, further research is required to answer the remaining questions, such as those concerning the optimal dosage and the controlled release of drugs.

\section{ORCID iDs}

Mohammed Moustafa Gad (D) https://orcid.org/0000-0003-3193-2356 Shaimaa Mohamed Fouda (D) https://orcid.org/0000-0002-3875-4882

\section{References}

1. Gendreau L, Loewy ZG. Epidemiology and etiology of denture stomatitis. J Prosthodont. 2011:20(4):251-260.

2. Newton AV. Denture sore mouth. A possible etiology. Br Dent J. 1962;112:357-360.

3. Silva Pinto TM, Claro Neves AC, Pereira Leão MV, Cardoso Jorge AO. Vinegar as an antimicrobial agent for control of Candida spp. in complete denture wearers. J Appl Oral Sci. 2008;16(6):385-390.

4. Taweechaisupapong S, Klanrit P, Singhara S, Pitiphat W, Wongkham S Inhibitory effect of Streblus asper leaf-extract on adhesion of Candida albicans to denture acrylic. J Ethnopharmacol. 2006;106(3):414-417.
5. Pires de Carvalho Bianchi CM, Bianchi HA, Tadano T, et al. Factors related to oral candidiasis in elderly users and non-users of removable dental prostheses. Rev Inst Med Trop Sao Paulo. 2016;58:17.

6. Bakhshi M, Taheri JB, Shabestari SB, Tanik A, Pahlevan R. Comparison of therapeutic effect of aqueous extract of garlic and nystatin mouthwash in denture stomatitis. Gerodontology. 2012;29(2):e680-e684.

7. Gebremedhin S, Dorocka-Bobkowska B, Prylinski M, Konopka K Duzgunes N. Miconazole activity against Candida biofilms developed on acrylic discs. J Physiol Pharmacol. 2014;65(4):593-600.

8. Davies A, Gebremedhin S, Yee M, et al. Cationic porphyrin-mediated photodynamic inactivation of Candida biofilms and the effect of miconazole. J Physiol Pharmacol. 2016;67(5):777-783.

9. Tsutsumi C, Takakuda K, Wakabayashi N. Reduction of Candida biofilm adhesion by incorporation of prereacted glass ionomer filler in denture base resin. J Dent. 2016;44:37-43.

10. Martins KV, de Lacerda Gontijo SL. Treatment of denture stomatitis: Literature review. Rev Bras Odontol. 2017;74(3):215-220.

11. Alavarce RAS, Saldanha LL, Almeida NLM, Porto VC, Dokkedal AL, Lara VS. The beneficial effect of Equisetum giganteum L. against Candida biofilm formation: New approaches to denture stomatitis. Evid Based Complement Alternat Med. 2015;2015:939625.

12. Marcos-Arias C, Eraso E, Madariaga L, Quindós G. In vitro activities of natural products against oral Candida isolates from denture wearers. BMC Complement Altern Med. 2011;11:119.

13. Pinelli LAP, Montandon AAB, Corbi SCT, Moraes TA, Fais LMG. Ricinus communis treatment of denture stomatitis in institutionalised elderly. J Oral Rehabil. 2013;40(5):375-380.

14. de MS Pinta G, Lia EN, Berretta AA, et al. Efficacy of propolis on the denture stomatitis treatment in older adults: A multicentric randomized trial. Evid Based Complement Alternat Med. 2017;2017:8971746.

15. Al-Dwairi ZN, Al-Quran FA, Al-Omari OY. The effect of antifungal agents on surface properties of poly(methyl methacrylate) and its relation to adherence of Candida albicans. J Prosthodont Res. 2012;56(4):272-280.

16. Shirley KP, Windsor LJ, Eckert GJ, Gregory RL. In vitro effects of Plantago major extract, aucubin, and baicalein on Candida albicans biofilm formation, metabolic activity, and cell surface hydrophobicity. J Prosthodont. 2017;26(6):508-515.

17. Machado-Gonçalves L, Tavares-Santos A, Santos-Costa F, et al. Effects of Terminalia catappa Linn. extract on Candida albicans biofilms developed on denture acrylic resin disc. J Clin Exp Dent. 2018;10(7):e642-e647.

18. Madeira PLB, Carvalho LT, Paschoal MAB, et al. In vitro effects of lemongrass extract on Candida albicans biofilms, human cells viability, and denture surface. Front Cell Infect Microbiol. 2016;6:71.

19. da Silva FC, Kimpara ET, Gasparotto Mancini MN, Balducci I, Cardoso Jorge AO, Koga-Ito CY. Effectiveness of six different disinfectants on removing five microbial species and effects on the topographic characteristics of acrylic resin. J Prosthodont. 2008;17(8):627-633.

20. Gornitsky M, ParadisI I, Landaverde G, Malo AM, Velly AM. A clinical and microbiological evaluation of denture cleansers for geriatric patients in long-term care institutions. J Can Dent Assoc. 2002;68(1):39-45.

21. Barnabé W, de Mendonça NT, Pimenta FC, Pegoraro LF, Scolaro JM. Efficacy of sodium hypochlorite and coconut soap used as disinfecting agents in the reduction of denture stomatitis, Streptococcus mutans and Candida albicans. J Oral Rehabil. 2004;31(5):453-459.

22. Cervantes Garcia de Sousa FA, Paradella TC, Koga-Ito CY, Cardoso Jorge AO. Effect of sodium bicarbonate on Candida albicans adherence to thermally activated acrylic resin. Braz Oral Res. 2009;23(4):381-385.

23. Ellepola AN, Samaranayake LP. Adjunctive use of chlorhexidine in oral candidoses: A review. Oral Dis. 2001;7(1):11-17.

24. Al-Thobity AM, Gad M, ArRejaie A, Alnassar T, Al-Khalifa KS. Impact of denture cleansing solution immersion on some properties of different denture base materials: An in vitro study. J Prosthodont. 2019;28(8):913-919.

25. Porwal A, Khandelwal M, Punia V, Sharma V. Effect of denture cleansers on color stability, surface roughness, and hardness of different denture base resins. J Indian Prosthodont Soc. 2017;17(1):61-67. 
26. Petrović $M$, Kostić $M$, Kostić $M$, et al. Therapeutic alternatives of natural compounds in treatment of Candida-associated denture stomatitis. Acta Med Median. 2014;53(1):73-80.

27. Waltimo T, Vallittu P, Haapasalo M. Adherence of Candida species to newly polymerized and water-stored denture base polymers. Int J Prosthodont. 2001;14(5):457-460.

28. Zamperini CA, Machado AL, Vergani CE, Pavarina AC, Giampaolo ET, da Cruz NC. Adherence in vitro of Candida albicans to plasma treated acrylic resin. Effect of plasma parameters, surface roughness and salivary pellicle. Arch Oral Biol. 2010;55(10):763-770.

29. Ali AA, Alharbi FA, Suresh CS. Effectiveness of coating acrylic resin dentures on preventing Candida adhesion. J Prosthodont. 2013;22(6):445-450.

30. Yodmongkol S, Chantarachindawong R, Thaweboon S, Thaweboon B, Amornsakchai T, Srikhirin T. The effects of silane-SiO $\mathrm{S}_{2}$ nanocomposite films on Candida albicans adhesion and the surface and physical properties of acrylic resin denture base material. J Prosthet Dent. 2014;112(6):1530-1538

31. Lazarin AA, Zamperini CA, Vergani CE, Wady AF, Giampaolo ET, Machado AL. Candida albicans adherence to an acrylic resin modified by experimental photopolymerised coatings: An in vitro study. Gerodontology. 2014;31(1):25-33.

32. Lazarin AA, Machado AL, Zamperini CA, Wady AF, Palomari Spolidorio DM, Vergani CE. Effect of experimental photopolymerized coatings on the hydrophobicity of a denture base acrylic resin and on Candida albicans adhesion. Arch Oral Biol. 2013;58(1):1-9.

33. Moura JS, da Silva WJ, Pereira T, Del Bel Cury AA, Rodrigues Garcia RC. Influence of acrylic resin polymerization methods and saliva on the adherence of four Candida species. J Prosthet Dent. 2006;96(3):205-211.

34. Hirasawa M, Tsutsumi-Arai C, Takakusaki K, Oya T, Fueki K, Wakabayashi N. Superhydrophilic co-polymer coatings on denture surfaces reduce Candida albicans adhesion - an in vitro study. Arch Oral Biol. 2018;87:143-150.

35. Zhou L, Tong Z, Wu G, et al. Parylene coating hinders Candida albicans adhesion to silicone elastomers and denture bases resin. Arch Oral Biol. 2010;55(6):401-409.

36. Park SE, Blissett R, Susarla SM, Weber HP. Candida albicans adherence to surface-modified denture resin surfaces. $J$ Prosthodont. 2008;17(5):365-369.

37. Azuma A, Akiba N, Minakuchi S. Hydrophilic surface modification of acrylic denture base material by silica coating and its influence on Candida albicans adherence. J Med Dent Sci. 2012;59(1):1-7.

38. Yoshijima Y, Murakami K, Kayama S, et al. Effect of substrate surface hydrophobicity on the adherence of yeast and hyphal Candida. Mycoses. 2010;53(3):221-226.

39. Tsuji M, Ueda T, Sawaki K, Kawaguchi M, Sakurai K. Biocompatibility of a titanium dioxide-coating method for denture base acrylic resin. Gerodontology. 2016;33(4):539-544.

40. Arai T, Ueda T, Sugiyama T, Sakurai K. Inhibiting microbial adhesion to denture base acrylic resin by titanium dioxide coating. J Oral Rehabil. 2009;36(12):902-908.

41. Sawada T, Sawada T, Kumasaka T, et al. Self-cleaning effects of acrylic resin containing fluoridated apatite-coated titanium dioxide. Gerodontology. 2014;31(1):68-75.

42. Al-Bakri IA, Harty D, Al-Omari WM, Swain MV, Chrzanowski W, Ellakwa A. Surface characteristics and microbial adherence ability of modified polymethylmethacrylate by fluoridated glass fillers. Aust Dent J. 2014;59(4):482-489.

43. Kamijo $K$, Mukai $Y$, Tominaga $T$, et al. Fluoride release and recharge characteristics of denture base resins containing surface pre-reacted glass-ionomer filler. Dent Mater J. 2009;28(2):227-233.

44. Totu EE, Nechifor AC, Nechifor G, Aboul-Enein HY, Cristache CM. Poly(methyl methacrylate) with $\mathrm{TiO}_{2}$ nanoparticles inclusion for stereolitographic complete denture manufacturing - the future in dental care for elderly edentulous patients? J Dent. 2017;59:68-77.

45. Gupta L, Aparna IN, Bhat S, Ginjupalli K. Effect of comonomer of methacrylic acid on flexural strength and adhesion of Staphylococcus aureus to heat polymerized poly (methyl methacrylate) resin: An in vitro study. J Indian Prosthodont Soc. 2017;17(2):149-155.
46. Marra J, Paleari AG, Rodriguez LS, Perin Leite AR, Pero AC, Compagnoni MA. Effect of an acrylic resin combined with an antimicrobial polymer on biofilm formation. J Appl Oral Sci. 2012;20(6):643-648.

47. Compagnoni MA, Pero AC, Ramos SMM, Marra J, Paleari AG, Rodriguez LS. Antimicrobial activity and surface properties of an acrylic resin containing a biocide polymer. Gerodontology. 2014;31(3):220-226.

48. Nawasrah A, AINimr A, Ali AA. Antifungal effect of henna against Candida albicans adhered to acrylic resin as a possible method for prevention of denture stomatitis. Int J Environ Res Public Health. 2016;13(5):520.

49. Al-Thobity AM, Al-Khalifa KS, Gad MM, Al-Hariri M, Ali AA, Alnassar T. In vitro evaluation of the inhibitory activity of thymoquinone in combatting Candida albicans in denture stomatitis prevention. Int J Environ Res Public Health. 2017;14(7):743.

50. Sivakumar I, Arunachalam KS, Sajjan S, Ramaraju AV, Rao B, Kamaraj B. Incorporation of antimicrobial macromolecules in acrylic denture base resins: A research composition and update. J Prosthodont. 2014;23(4):284-290.

51. Anwander M, Rosentritt M, Schneider-Feyrer S, Hahnel S. Biofilm formation on denture base resin including $\mathrm{ZnO}, \mathrm{CaO}$, and $\mathrm{TiO}_{2}$ nanoparticles. J Adv Prosthodont. 2017;9(6):482-485.

52. Li Z, Sun J, Lan J, Qi Q. Effect of a denture base acrylic resin containing silver nanoparticles on Candida albicans biofilm formation. Gerodontology. 2016;33(2):209-216.

53. Nam KY, Lee CH, Lee CJ. Antifungal and physical characteristics of modified denture base acrylic incorporated with silver nanoparticles. Gerodontology. 2012;29(2):e413-e419.

54. Suganya S, Ahila SC, Kumar BM, Kumar MV. Evaluation and comparison of anti-Candida effect of heat cure polymethylmethacrylate resin enforced with silver nanoparticles and conventional heat cure resins: An in vitro study. Indian J Dent Res. 2014;25(2):204-207.

55. Srivastava R, Sharma V, Dave A, Upadhyay M. Silver nanoparticles in denture base material. Int J Prev Clin Dent Res. 2016;3(4):267-270.

56. Casemiro LA, Gomes Martins CH, Pires-de-Souza Fde C, Panzeri H. Antimicrobial and mechanical properties of acrylic resins with incorporated silver-zinc zeolite - part I. Gerodontology. 2008;25(3):187-194.

57. Monteiro DR, Gorup LF, Takamiya AS, de Camargo ER, Ruvolo Filho AC, Barbosa DB. Silver distribution and release from an antimicrobial denture base resin containing silver colloidal nanoparticles. J Prosthodont. 2012;21(1):7-15.

58. Wady AF, Machado AL, Zucolotto V, Zamperini CA, Berni E, Vergani CE. Evaluation of Candida albicans adhesion and biofilm formation on a denture base acrylic resin containing silver nanoparticles. J Appl Microbiol. 2012;112(6):1163-1172.

59. Su W, Wang S, Wang $X, F u$ X, Weng J. Plasma pre-treatment and $\mathrm{TiO}_{2}$ coating of PMMA for the improvement of antibacterial properties. Surf Coat Techn. 2010;205(2):465-469.

60. Kamonkhantikul K, Arksornnukit M, Takahashi H. Antifungal, optical, and mechanical properties of polymethylmethacrylate material incorporated with silanized zinc oxide nanoparticles. Int J Nanomedicine. 2017;12:2353-2360.

61. Gad MM, Abualsaud R. Behavior of PMMA denture base materials containing titanium dioxide nanoparticles: A literature review. Int J Biomater. 2019;2019:6190610. 